\title{
A) P28
}

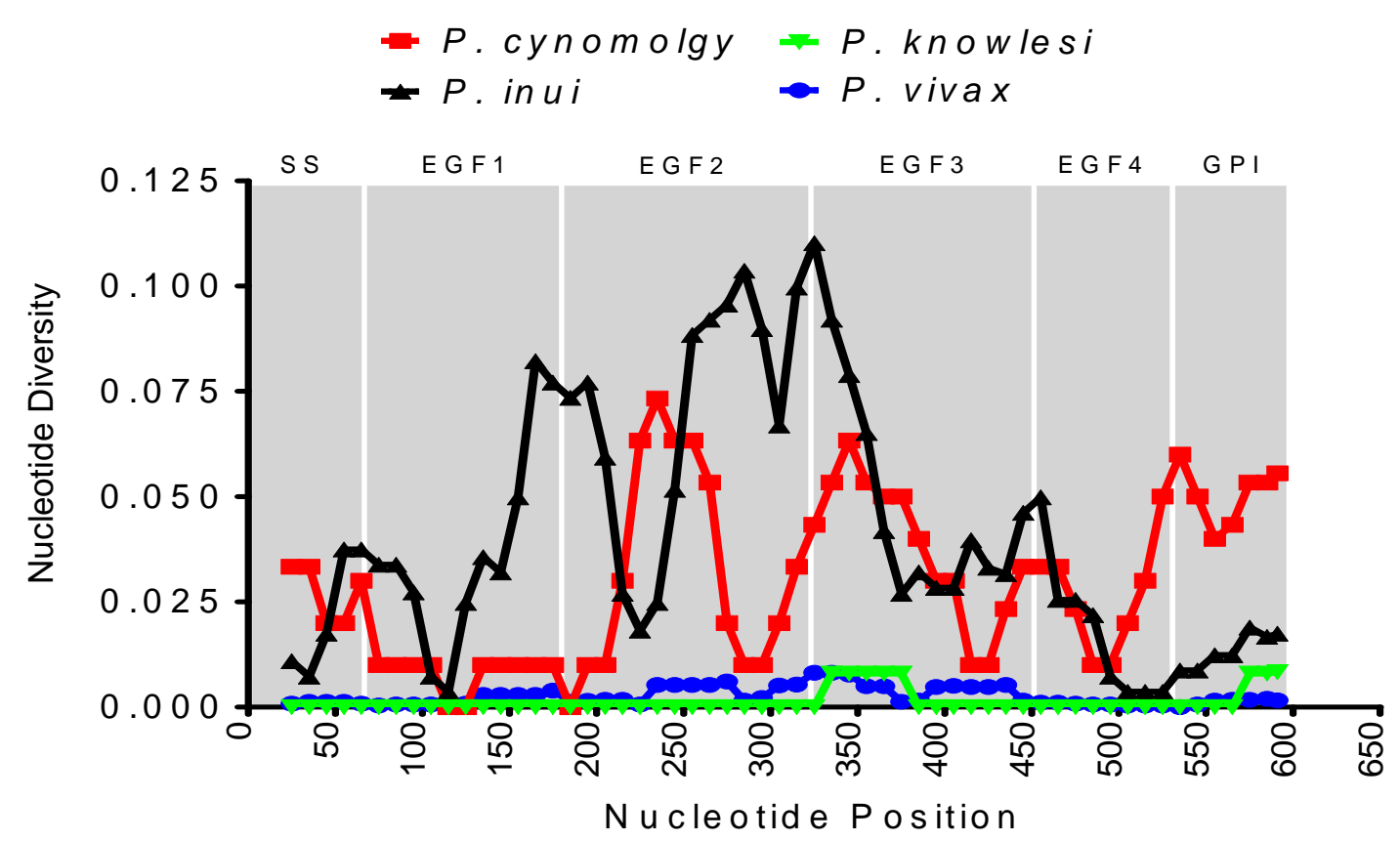

B) P28 (P. cynomolgi)

- P28 orthologous B -062530

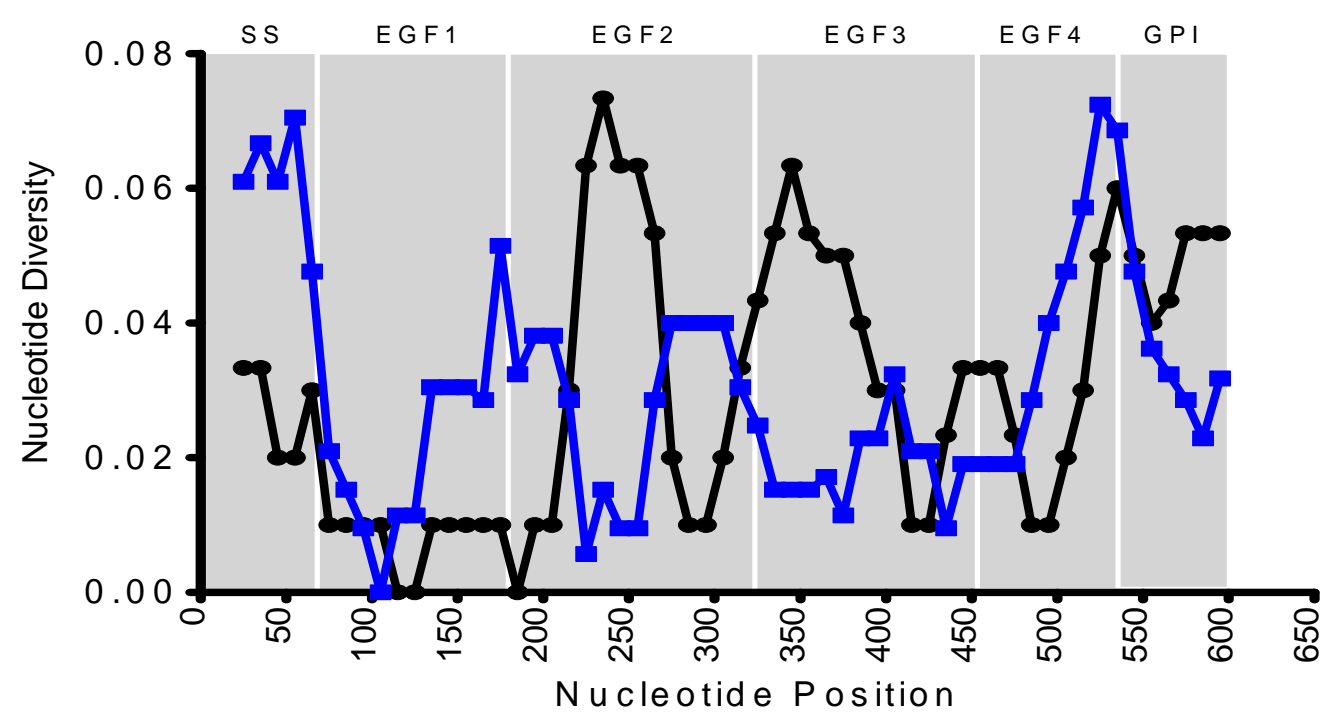

C) P25

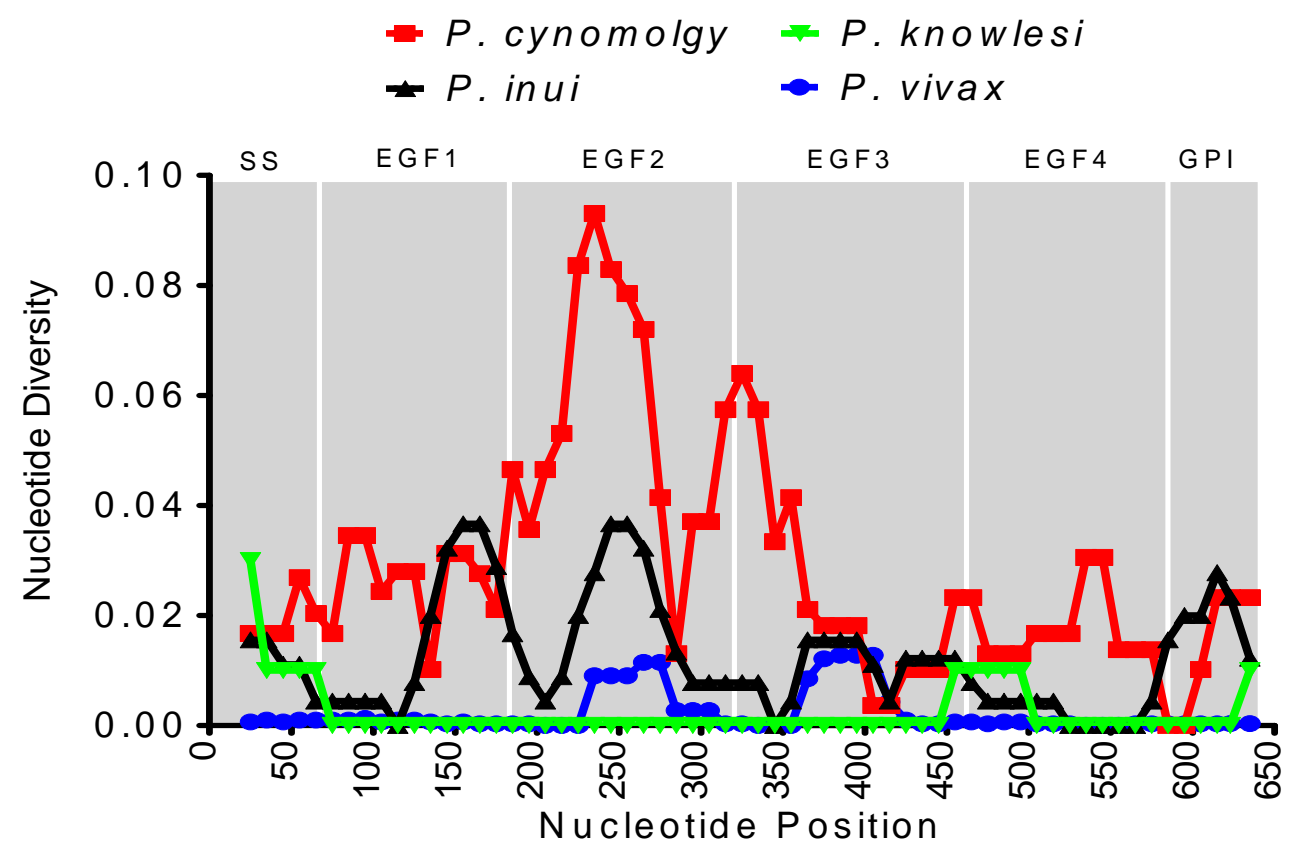

